\title{
Effect of Simultaneous Mechanical and Electrical Stress on the Electrical Performance of Flexible In-Ga-Zn-O Thin-Film Transistors
}

\author{
Youngjin Seo ${ }^{1}$, Hwan-Seok Jeong ${ }^{2}$, Ha-Yun Jeong ${ }^{2}$, Shinyoung Park ${ }^{1}$, Jun Tae Jang ${ }^{1}$, \\ Sungju Choi ${ }^{1}{ }^{1}$, Dong Myong Kim ${ }^{1}$, Sung-Jin Choi ${ }^{1}$, Xiaoshi Jin ${ }^{3}$, Hyuck-In Kwon ${ }^{2, *}$ \\ and Dae Hwan Kim ${ }^{1, *(D)}$ \\ 1 School of Electrical Engineering, Kookmin University, Seoul 02707, Korea; ssoocw1535@kookmin.ac.kr (Y.S.); \\ shinyoung94@kookmin.ac.kr (S.P.); jtjang@kookmin.ac.kr (J.T.J.); sungjuchoi@kookmin.ac.kr (S.C.); \\ dmkim@kookmin.ac.kr (D.M.K.); sjchoiee@kookmin.ac.kr (S.-J.C.) \\ 2 School of Electrical and Electronics Engineering, Chung-Ang University, Seoul 06974, Korea; \\ hwanseok518@cau.ac.kr (H.-S.J.); seonmmmn9@cau.ac.kr (H.-Y.J.) \\ 3 School of Information Science and Engineering, Shenyang University of Technology, \\ Shenyang 110870, China; xsjin@live.cn \\ * Correspondence: hyuckin@cau.ac.kr (H.-I.K.); drlife@kookmin.ac.kr (D.H.K.)
}

Received: 11 September 2019; Accepted: 2 October 2019; Published: 4 October 2019

\begin{abstract}
We investigated the effect of simultaneous mechanical and electrical stress on the electrical characteristics of flexible indium-gallium-zinc oxide (IGZO) thin-film transistors (TFTs). The IGZO TFTs exhibited a threshold voltage shift $\left(\Delta V_{\mathrm{TH}}\right)$ under an application of positive-bias-stress (PBS), with a turnaround behavior from the positive $\Delta V_{\mathrm{TH}}$ to the negative $\Delta V_{\mathrm{TH}}$ with an increase in the PBS application time, whether a mechanical stress is applied or not. However, the magnitudes of PBS-induced $\Delta V_{\mathrm{TH}}$ in both the positive and negative directions exhibited significantly larger values when a flexible IGZO TFT was under mechanical-bending stress than when it was at the flat state. The observed phenomena were possibly attributed to the mechanical stress-induced interface trap generation and the enhanced hydrogen diffusion from atomic layer deposition-grown $\mathrm{Al}_{2} \mathrm{O}_{3}$ to IGZO under mechanical-bending stress during PBS. The subgap density of states was extracted before and after an application of PBS under both mechanical stress conditions. The obtained results in this study provided potent evidence supporting the mechanism suggested to explain the PBS-induced larger $\Delta V_{\mathrm{TH}} \mathrm{s}$ in both directions under mechanical-bending stress.
\end{abstract}

Keywords: Flexible IGZO TFTs; $\mathrm{Al}_{2} \mathrm{O}_{3}$ gate dielectric; simultaneous mechanical and electrical stress; hydrogen

\section{Introduction}

Indium-gallium-zinc oxide (IGZO) thin-film transistor (TFT) is being widely used for the backplane of large-area active-matrix organic-light-emitting diode displays, owing to its excellent properties including high field-effect mobility $\left(\mu_{\mathrm{FE}}\right)$, low-off current, high uniformity, and low process temperature [1-11]. Recently, there is increasing interest in the application of IGZO TFTs in demonstrating the active-matrix backplane for flexible displays [12-16]. Flexible displays have many advantages over conventional glass substrate-based displays including better durability, lighter weight, and thinner dimension. In addition, flexible displays can enable a lot of new applications because of their ability to have unique curved shapes.

Nevertheless, there are still reliability problems that should be solved for practical applications of IGZO TFTs to the active-matrix backplane of flexible displays. As flexible displays can experience 
an external mechanical stress depending on the bending radius and direction, the IGZO TFTs can be subjected to the simultaneous mechanical and electrical stress when they are used for the backplane of flexible displays. However, unfortunately, there have been very few studies that examined the effect of simultaneous mechanical and electrical stress on the electrical properties of flexible IGZO TFTs, even though various studies were already conducted on the electrical or mechanical stress-induced performance degradation in IGZO TFTs [17-22]. In this work, we compared the positive-bias-stress (PBS)-induced instability of IGZO TFTs under mechanical-bending stress and no mechanical stress by using the flexible TFTs fabricated on the plastic substrate with an $\mathrm{Al}_{2} \mathrm{O}_{3}$ gate insulator deposited using the atomic layer deposition (ALD) technique. Our experimental results showed that the IGZO TFTs exhibited a threshold voltage shift $\left(\Delta V_{\mathrm{TH}}\right)$ under an application of PBS with a turnaround behavior from the positive $\Delta V_{\mathrm{TH}}$ to the negative $\Delta V_{\mathrm{TH}}$ with an increase in the stress time regardless of an application of the mechanical stress. However, the magnitudes of $\Delta V_{\mathrm{TH}}$ in both the positive and negative directions exhibited larger values when a flexible IGZO TFT was under mechanical-bending stress than it was at the flat state. To find out the physical mechanism for the observed phenomenon, the subgap density of states (DOS) was extracted from the fabricated flexible IGZO TFTs before and after PBS application under mechanical-bending stress and no mechanical stress, respectively. The extracted values at each condition were correlated with larger magnitudes of PBS-induced $\Delta V_{\mathrm{TH}} \mathrm{s}$ in the IGZO TFT under mechanical-bending stress compared to that at the flat state.

\section{Experimental Procedure}

Figure 1a displays the schematic cross-sectional image of the flexible IGZO TFT fabricated on the polyethylene terephthalate (PET) substrate. The substrate was attached to a silicon wafer during the whole TFT fabrication process and separated from that when the TFT fabrication was completed. First, a 50-nm-thick $\mathrm{SiO}_{2}$ buffer layer was formed on the PET by e-beam evaporation. Next, a 20-nm-thick $\mathrm{Cu}$ film was deposited using e-beam evaporation and patterned to form the gate electrode. Then, a gate dielectric of 40-nm-thick $\mathrm{Al}_{2} \mathrm{O}_{3}$ was formed, using $\mathrm{ALD}$ at a low temperature of $80{ }^{\circ} \mathrm{C}$, to avoid thermal damage on the PET substrate by utilizing $\mathrm{Al}\left(\mathrm{CH}_{3}\right)_{3}$ (trimethylaluminum-TMA) and water as precursors. A 35-nm-thick IGZO channel layer was formed by reactive sputtering using a polycrystalline IGZO target $\left(\mathrm{In}_{2} \mathrm{O}_{3}: \mathrm{Ga}_{2} \mathrm{O}_{3}: \mathrm{ZnO}=1: 1: 1 \mathrm{~mol} \%\right)$ at room temperature (RT). A 40-nm-thick $\mathrm{Cu}$ film was deposited and patterned to form the source/drain electrodes. Finally, the device was thermally annealed at $150^{\circ} \mathrm{C}$ for 1 hour in air. Figure $1 b, c$ display the photographic images of the fabricated IGZO TFT on the flexible PET substrate.

(a)

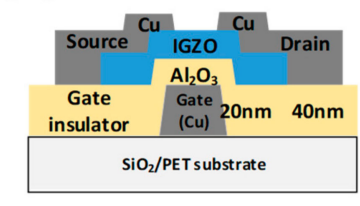

(c)

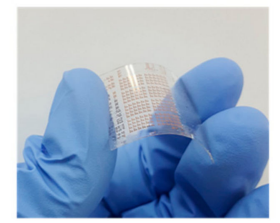

(b)

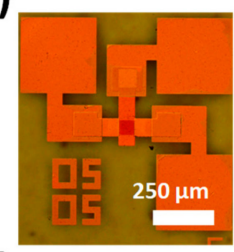

(d)

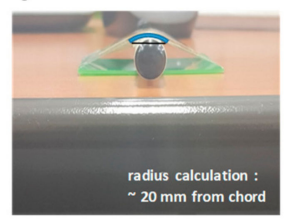

Figure 1. (a) Schematic cross-sectional image of the flexible indium-gallium-zinc oxide (IGZO) thin-film transistor (TFT) fabricated on the polyethylene terephthalate (PET) substrate. (b), (c) Photographic images of the fabricated flexible IGZO TFT. (d) Photographic image of the customized bending plate with a $20 \mathrm{~mm}$ bending radius. 
The electrical parameters extracted from the representative device were as follows: A $V_{\mathrm{TH}}$ of 1.8 $\mathrm{V}$; a $\mu_{\mathrm{FE}}$ of $7.3 \mathrm{~cm}^{2} / \mathrm{Vs}$; and a subthreshold swing of $0.32 \mathrm{~V} / \mathrm{dec}$. Here, $V_{\mathrm{TH}}$ was defined as the value of gate-to-source voltage $\left(V_{\mathrm{GS}}\right)$ inducing the drain current $\left(I_{\mathrm{D}}\right)$ of a width/length $(W / L) \times 10 \mathrm{nA}$ at a drain-to-source voltage $\left(V_{\mathrm{DS}}\right)$ of $5 \mathrm{~V}[23,24]$. The mechanical stress was applied to the TFTs by using the customized bending plate with a $\sim 20 \mathrm{~mm}$ bending radius (Figure $1 \mathrm{~d}$ ). The direction of bending was outward with respect to the flexible substrate (tensile stress) and parallel to the source-drain current path. The electrical properties of the devices were evaluated in the dark at RT using an Agilent 4156C precision semiconductor parameter analyzer. In addition, to remove the ambient effects on the experimental results [25-27], the electrical characterization was conducted in a 10 mTorr vacuum environment.

\section{Results and Discussion}

Figure 2a,b display the change of transfer curves as a function of the applied stress time under a positive $V_{\mathrm{GS}}$ of $8 \mathrm{~V}$ in flexible IGZO TFTs at the flat state and under the mechanical-bending stress, respectively. Measurements were made for TFTs with a $W / L$ of $5 \mu \mathrm{m} / 20 \mu \mathrm{m}$ at a $V_{\mathrm{DS}}$ of $5 \mathrm{~V}$ at RT. Figure 2a,b show that the IGZO TFTs exhibit $V_{\mathrm{TH}}$ turnaround characteristics under both mechanical stress conditions. $V_{\mathrm{TH}}$ shifts in the positive direction during the initial $500 \mathrm{~s}$; but shifts in the negative direction after $500 \mathrm{~s}$ of stress. In previous works, the PBS-induced $V_{\mathrm{TH}}$ turnaround behavior was already observed in IGZO TFTs with a low-temperature $\mathrm{ALD} \mathrm{Al}_{2} \mathrm{O}_{3}$ gate dielectric and was mainly ascribed to the effect of electron trapping and hydrogen release and diffusion [28]. The positive shift of $V_{\mathrm{TH}}$ at the initial stage of PBS was explained by the electron trapping in traps at the $\mathrm{Al}_{2} \mathrm{O}_{3} / \mathrm{IGZO}$ interface or bulk $\mathrm{Al}_{2} \mathrm{O}_{3}$, and the negative shift of $V_{\mathrm{TH}}$ after a long stress time was mainly attributed to the hydrogen diffusion from a low-temperature $\mathrm{ALD} \mathrm{Al}_{2} \mathrm{O}_{3}$ gate dielectric into an IGZO layer. The hydrogen atom was assumed to be generated from the breakage of residual $\mathrm{AlO}-\mathrm{H}$ bonds in the ALD $\mathrm{Al}_{2} \mathrm{O}_{3}$ by the energetic electrons in the TFT channel during PBS application [28]. When $\mathrm{Al}_{2} \mathrm{O}_{3}$ is deposited using ALD at low temperatures, the chemical reaction between AlO-H and TMA is less complete, which causes considerable $\mathrm{AlO}-\mathrm{H}$ residues in $\mathrm{Al}_{2} \mathrm{O}_{3}$ [29]. As hydrogen is the effective donor in IGZO through the reaction of $\mathrm{H}^{0}+\mathrm{O}^{2-} \rightarrow \mathrm{OH}^{-}+\mathrm{e}^{-}$[30], the hydrogen doping shifts the $V_{\mathrm{TH}}$. of the IGZO TFT in the negative direction.
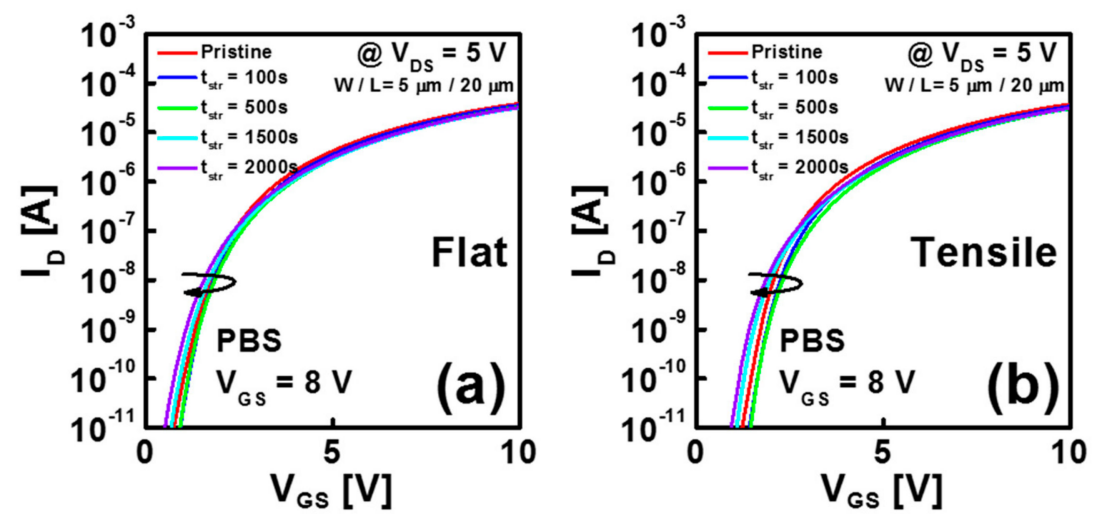

Figure 2. Change of transfer curves as a function of the applied stress time under a $V_{\mathrm{GS}}$ stress of $8 \mathrm{~V}$ in flexible IGZO TFTs (a) at the flat state and (b) under the mechanical-bending stress.

Figure 3 displays the schematic energy band diagram which illustrates the effects of electron trapping and hydrogen release and diffusion on the $V_{\mathrm{TH}}$ of IGZO TFTs. Figure 4 shows the $\Delta V_{\mathrm{TH}}$ versus stress time extracted from Figure 2a,b. From Figure 4, we can clearly observe that the magnitudes of $\Delta V_{\mathrm{TH}}$ in both the positive and negative directions exhibit larger values when a flexible IGZO TFT is subjected to the mechanical stress than when it is at the flat state. As far as we know, this is a phenomenon that has not been reported in the previous works. Considering that the IGZO TFT are 
subjected to the simultaneous mechanical and electrical stress when they are used for the backplane of flexible displays, it is very important to analyze the phenomenon observed in Figure 4.

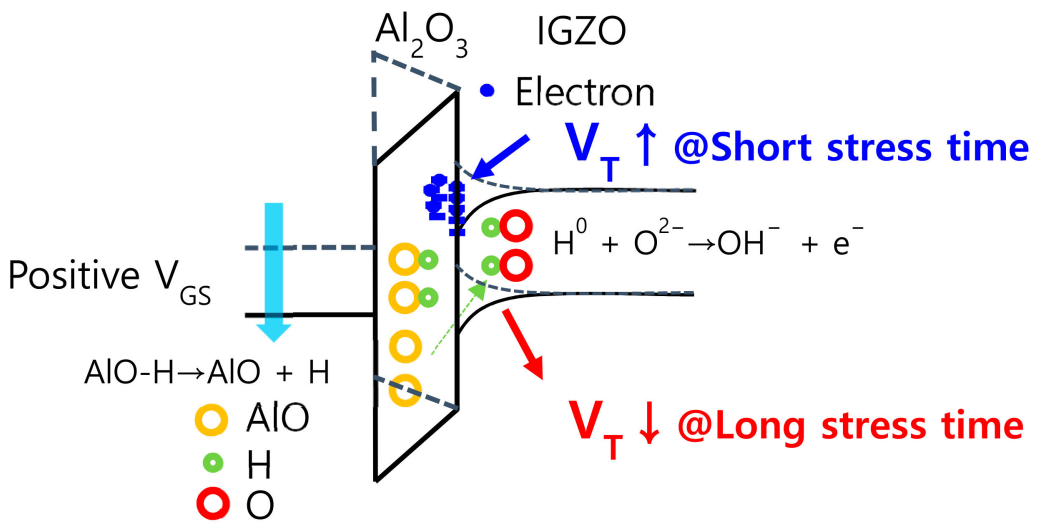

Figure 3. Schematic energy band diagram which illustrates the effects of electron trapping and hydrogen release and diffusion on the $V_{\mathrm{TH}}$ of IGZO TFTs.

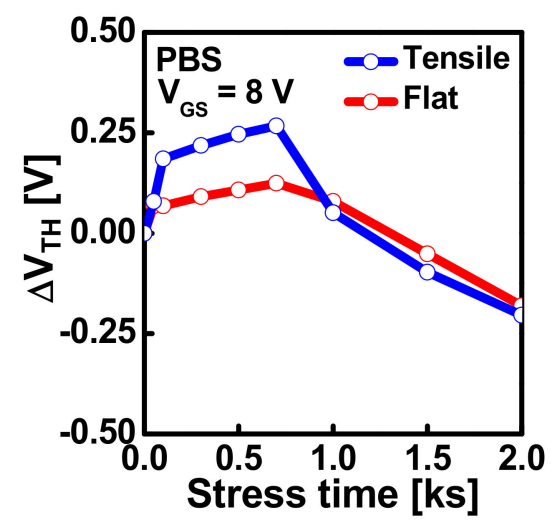

Figure 4. $\Delta V_{\mathrm{TH}}$ versus stress time under a $V_{\mathrm{GS}}$ stress of $8 \mathrm{~V}$ in flexible IGZO TFTs at the flat state and under tensile bending stress.

To find out the physical mechanism for the observed phenomenon in Figure 4, the subgap DOS were extracted from the IGZO TFTs before and after PBS application under mechanical-bending stress and no mechanical stress, respectively, using the monochromatic photonic capacitance-voltage $(C-V)$ technique [31]. Figure 5 displays the energy distribution of the subgap DOS obtained from the IGZO TFTs under mechanical-bending stress and no mechanical stress before PBS application, respectively. Figure 5 displays that the density of tail states near the conduction band edge $\left(E_{\mathrm{C}}\right)$ extracted from the IGZO TFT under mechanical-bending stress are higher than that extracted from the TFT at the flat state, which is possibly ascribed to the larger number of structural defects at the interface in the mechanically-bended IGZO TFT due to different Young's modulus values of $\mathrm{Al}_{2} \mathrm{O}_{3}$ ( $300 \mathrm{GPa}$ ) and IGZO (137 GPa) [27]. When the same strain is applied to each layer, the $\mathrm{Al}_{2} \mathrm{O}_{3}$ gate insulator undergoes larger stress compared to IGZO channel layer, which can generate the structural defects at the interface between $\mathrm{Al}_{2} \mathrm{O}_{3}$ and IGZO. As the interface trap states act as the electron trapping sites during PBS application in IGZO TFTs, it can explain the large positive shift of $V_{\mathrm{TH}}$ at the initial stage of PBS in the mechanically-bended IGZO TFT in Figure 4 [32]. From Figure 5, we can also observe that not only the density of tail states but the subgap DOS at $0.1-0.3 \mathrm{eV}$ below $E_{\mathrm{C}}$ exhibits larger values in the mechanically-bended IGZO TFT than in the IGZO TFT at the flat state. In previous works, the mechanical strain was reported to generate the oxygen vacancies in IGZO, including ionized ones $[20,21]$. Considering that the increase in the donorlike states at $\sim E_{\mathrm{C}}-(0.1-0.3 \mathrm{eV})$ is most likely to result from the increase in the ionized oxygen vacancies in IGZO [33,34], an increase in the subgap 
DOS at $0.1-0.3 \mathrm{eV}$ below $E_{\mathrm{C}}$ in Figure 5 can be possibly ascribed to the increased oxygen vacancies in IGZO due to the mechanical bending stress.

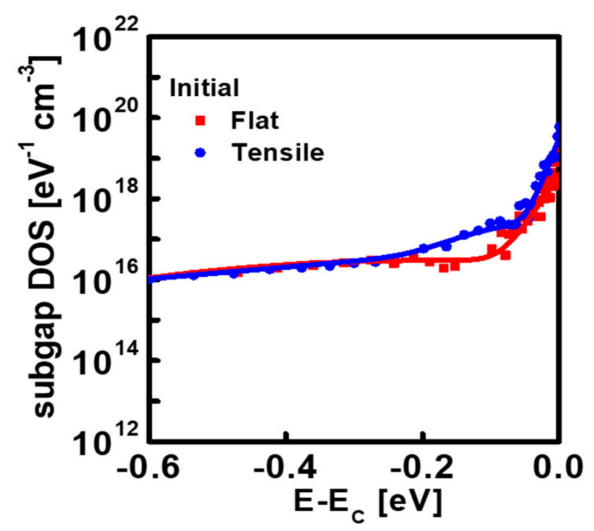

Figure 5. Energy distribution of the subgap density of states (DOS) obtained from the IGZO TFTs before positive-bias-stress (PBS) application under the tensile bending stress and no mechanical stress.

Figure 6a,b compares the subgap DOS extracted from the IGZO TFTs before and after PBS application (stress time: $2000 \mathrm{~s}$ ) at the flat state and under the mechanical-bending stress, respectively. Figure 6 shows that the subgap DOS near $E_{C}$ increases after PBS application under both mechanical conditions. However, it increases more pronouncely after PBS in the IGZO TFT under mechanical bending stress than that at the flat state. In previous reports, the negative shift of $V_{\mathrm{TH}}$ after a long stress time was mainly attributed to the hydrogen diffusion from a low-temperature $\mathrm{ALD} \mathrm{Al}_{2} \mathrm{O}_{3}$ gate dielectric into an IGZO layer [28]. As the hydrogen acts as an effective donor in IGZO, it generates the donor states near $E_{\mathrm{C}}$ and shifts the $V_{\mathrm{TH}}$ of the IGZO TFT in the negative direction. The PBS-induced increase of subgap DOS near $E_{C}$ observed in Figure 6 is possibly ascribed to the increase of the hydrogen concentration inside the IGZO after PBS application. In addition, a more pronounced increase of subgap DOS near $E_{C}$ in the IGZO TFT under mechanical-bending stress is considered as a result of more enhanced hydrogen diffusion from $\mathrm{Al}_{2} \mathrm{O}_{3}$ gate dielectric into an IGZO layer in the mechanically stressed IGZO TFT. This result is consistent with that in Figure 4, which shows a more pronounced negative shift of $V_{\mathrm{TH}}$ after a long stress time in the mechanically stressed IGZO TFT. More enhanced hydrogen diffusion in the mechanically stressed IGZO TFT is believed to be caused from the increased oxygen vacancies which can act as the hydrogen hopping site in IGZO. Figure 7 displays the schematic diagram illustrating the mechanism responsible for more enhanced hydrogen diffusion form ALD $\mathrm{Al}_{2} \mathrm{O}_{3}$ gate dielectric into an IGZO layer in IGZO TFTs under mechanical stress.
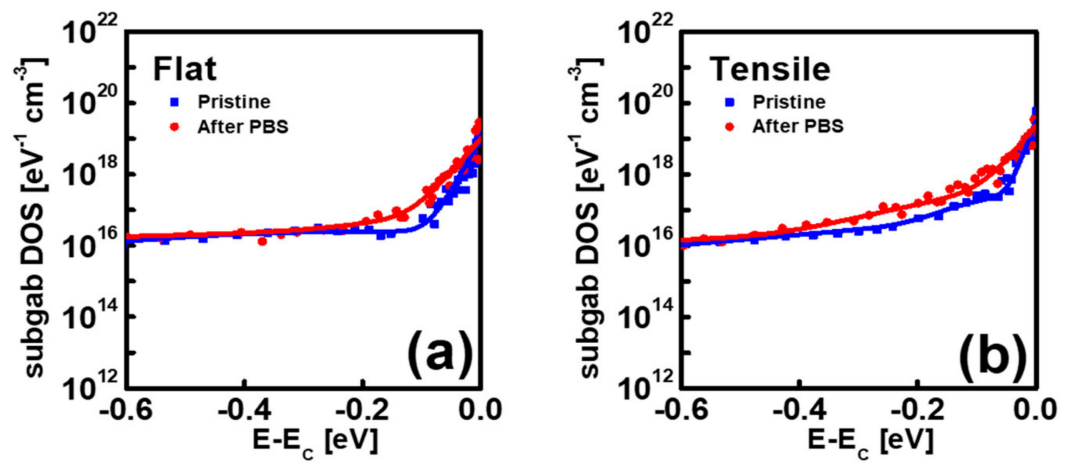

Figure 6. Energy distribution of the subgap DOS obtained from the IGZO TFTs before and after PBS application (stress time: 2000 s) (a) at the flat state and (b) under tensile bending stress. 


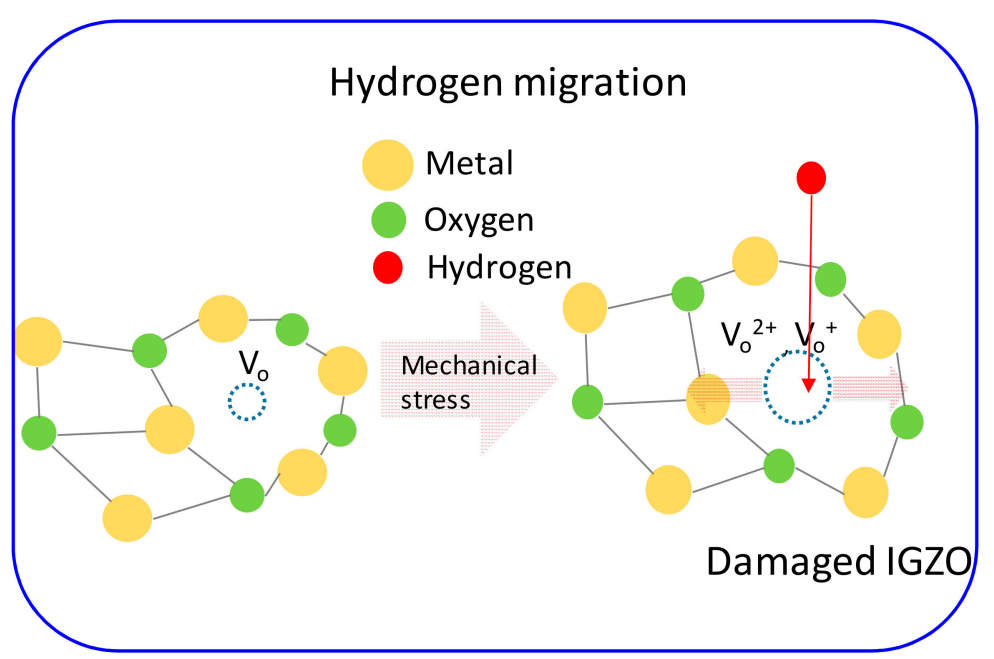

Figure 7. Schematic diagram illustrating the physical mechanism responsible for more enhanced hydrogen diffusion form atomic layer deposition (ALD) $\mathrm{Al}_{2} \mathrm{O}_{3}$ gate dielectric into an IGZO layer in IGZO TFTs under mechanical bending stress.

\section{Conclusions}

In this research, we compared the PBS-induced instability of IGZO TFTs under the mechanical-bending stress and no mechanical stress by using the flexible IGZO TFTs fabricated with a low-temperature ALD $\mathrm{Al}_{2} \mathrm{O}_{3}$ gate dielectric. The IGZO TFTs exhibited a $\Delta V_{\mathrm{TH}}$ under an application of PBS with a turnaround behavior from the positive $\Delta V_{\mathrm{TH}}$ to the negative $\Delta V_{\mathrm{TH}}$ under both mechanical stress conditions. The magnitudes of $\Delta V_{\mathrm{TH}}$ in both directions exhibited higher values when a flexible IGZO TFT was mechanically bended than it was at the flat state. The observed phenomena were considered as a result of the additional interface trap generation and the enhanced hydrogen diffusion from $\mathrm{ALD} \mathrm{Al}_{2} \mathrm{O}_{3}$ to IGZO by the mechanical-bending stress during an application of PBS. The subgap DOS was extracted before and after an application of PBS under both mechanical stress conditions using the monochromatic photonic $C-V$ technique. The obtained results were correlated with a PBS-induced larger $\Delta V_{\mathrm{TH}} \mathrm{s}$ in both directions under mechanical-bending stress as compared to at the flat state. To fully understand the degradation mechanism, a further study that compares the effects of simultaneous mechanical and electrical stress in flexible IGZO TFTs having $\mathrm{Al}_{2} \mathrm{O}_{3}$ gate dielectrics with different hydrogen contents needs to be conducted in the future.

Author Contributions: Conceptualization, Y.S., H.-I.K., and D.H.K.; experiment, Y.S., H.-S.J., H.-Y.J., S.P., J.T.J. and S.C.; data analysis, Y.S., H.-S.J., H.-Y.J., D.M.K., S.-J.C., X.J., H.-I.K., and D.H.K., writing-original draft preparation, Y.S.; supervision, H.-I.K. and D.H.K.; writing-review and editing, H.-I.K.

Funding: This work was supported by the national research foundation (NRF) of Korea funded by the Korean government under Grant 2016R1A5A1012966, 2016M3A7B4909668, 2017R1A2B4006982, 2017R1A2A2A14001213 and in part by an Electronics and Telecommunications Research Institute (ETRI) grant funded by the Korean government (18ZB1800).

Conflicts of Interest: The authors declare no conflict of interest.

\section{References}

1. Nomura, K.; Ohta, H.; Takagi, A.; Kamiya, T.; Hirano, M.; Hosono, H. Room-temperature fabrication of transparent flexible thin-film transistors using amorphous oxide semiconductors. Nature 2004, 432, 488-492. [CrossRef] [PubMed]

2. Geng, D.; Kang, D.H.; Jang, J. High.-performance amorphous Indium-Gallium-Zinc-Oxide thin-film transistor with a self-aligned etch stopper patterned by back-side UV exposure. IEEE Electron Device Lett. 2011, 32, 758-760. [CrossRef]

3. Fortunato, E.; Barquinha, P.; Martins, R. Oxide semiconductor thin-film transistors: A review of recent advances. Adv. Mater. 2012, 24, 2945-2986. [CrossRef] 
4. Lee, U.G.; Mativeng, M.; Kang, D.H.; Jang, J. A Three-Mask-Processed Coplanar a-IGZO TFT with Source and Drain. Offsets. IEEE Electron Device Lett. 2012, 33, 812-814. [CrossRef]

5. Zhang, J.; Yang, J.; Li, Y.; Wilson, J.; Ma, X.; Xin, Q.; Song, A. High performance complementary circuits based on p-SnO and n-IGZO thin-film transistors. Materials 2017, 10, 319. [CrossRef] [PubMed]

6. Kim, K.S.; Ahn, C.H.; Kang, W.J.; Cho, S.W.; Jung, S.H.; Yoon, D.H.; Cho, H.K. An. all oxide-based imperceptible thin-film transistor with humidity sensing properties. Materials 2017, 10, 530. [CrossRef]

7. Jeong, C.Y.; Kim, H.J.; Hong, S.Y.; Song, S.H.; Kwon, H.I. Two-stage unified stretched-exponential model for time-dependence of threshold voltage shift under positive-bias-stresses in amorphous indium-gallium-zinc oxide thin-film transistors. Jpn. J. Appl. Phys. 2017, 56, 080301. [CrossRef]

8. Han, K.L.; Cho, H.S.; Ok, K.C.; Oh, S.; Park, J.S. Comparative Study on Hydrogen Behavior in InGaZnO Thin Film Transistors with a $\mathrm{SiO}_{2} / \mathrm{SiN}_{\mathrm{x}} / \mathrm{SiO}_{2}$ Buffer on Polyimide and Glass Substrates. Electr. Mater. Lett. 2018, 14, 749-754. [CrossRef]

9. Yoon, S.J.; Seong, N.J.; Choi, K.J.; Shin, W.C.; Yoon, S.M. Investigations on the bias temperature stabilities of oxide thin film transistors using In-Ga-Zn-O channels prepared by atomic layer deposition. RSC Adv. 2018, 8, 25014-25020. [CrossRef]

10. Choi, S.B.; Kim, K.T.; Park, S.K.; Kim, Y.H. High-Mobility Inkjet-Printed Indium-Gallium-Zinc-Oxide Thin-Film Transistors Using Sr-Doped Al2O3 Gate Dielectric. Materials 2019, 12, 852.

11. Hong, S.Y.; Kim, H.J.; Kim, D.H.; Jeong, H.Y.; Song, S.H.; Cho, I.T.; Noh, J.Y.; Yun, P.S.; Lee, S.W.; Park, K.S.; et al. Study on the Lateral Carrier Diffusion and Source-Drain. Series Resistance in Self-Aligned Top.-Gate Coplanar InGaZnO Thin-Film Transistors. Sci. Rep. 2019, 9, 6588. [CrossRef] [PubMed]

12. Munzenrieder, N.; Voser, P.; Petti, L.; Zysset, C.; Buthe, L.; Vogt, C.; Salvatore, G.A.; Troster, G. Flexible Self-Aligned Double-Gate IGZO TFT. IEEE Electron Device Lett. 2014, 35, 69-71. [CrossRef]

13. Kumaresan, Y.; Pak, Y.; Lim, N.; Kim, Y.; Park, M.J.; Yoon, S.M.; Youn, H.M.; Lee, H.; Lee, B.H.; Jung, G.Y. Highly Bendable In-Ga-ZnO Thin Film Transistors by Using a Thermally Stable Organic Dielectric Layer. Sci. Rep. 2016, 6, 37764. [CrossRef]

14. Yao, R.; Zheng, Z.; Xiong, M.; Zhang, X.; Li, X.; Ning, H.; Fang, Z.; Xie, W.; Lu, X.; Peng, J. Low-temperature fabrication of sputtered high-k $\mathrm{HfO}_{2}$ gate dielectric for flexible a-IGZO thin film transistors. Appl. Phys. Lett. 2018, 112, 103503. [CrossRef]

15. Jang, H.W.; Kim, H.R.; Yang, J.H.; Byun, C.W.; Kang, C.S.; Kim, S.K.; Yoon, S.M. Stability improvements of InGaZnO thin-film transistors on polyimide substrates with $\mathrm{Al}_{2} \mathrm{O}_{3}$ buffer layer. Jpn. J. Appl. Phys. 2018, 57, 090313. [CrossRef]

16. Zhang, L.; Xiao, W.; Wu, W.; Liu, B. Research Progress on Flexible Oxide-Based Thin Film Transistors. App. Sci. 2019, 9, 773. [CrossRef]

17. Fujii, M.; Uraoka, Y.; Fuyuki, T.; Jung, J.S.; Kwon, J.Y. Experimental and Theoretical Analysis of Degradation in $\mathrm{Ga}_{2} \mathrm{O}_{3}-\mathrm{In}_{2} \mathrm{O}_{3}-\mathrm{ZnO}$ Thin-Film Transistors. Jpn. J. Appl. Phys. 2009, 48, 04C091. [CrossRef]

18. Lee, S.W.; Jeon, K.C.; Park, J.-H.; Kim, S.C.; Kong, D.S. Electrical stress-induced instability of amorphous indium-gallium-zinc oxide thin-film transistors under bipolar ac stress. Appl. Phys. Lett. 2009, 95, 132101. [CrossRef]

19. Mativenga, M.; Seok, M.J.; Jang, J. Gate bias-stress induced hump-effect in transfer characteristics of amorphous-indium-galium-zinc-oxide thin-fim transistors with various channel widths. Appl. Phys. Lett. 2011, 99, 122107. [CrossRef]

20. Liao, P.Y.; Chang, T.C.; Su, W.C.; Chen, Y.J.; Chen, B.W.; Hsieh, T.Y.; Yang, C.Y.; Huang, Y.Y.; Chang, H.M.; Chiang, S.C. Effect of mechanical-strain-induced defect generation on the performance of flexible amorphous In-Ga-Zn-O thin-film transistors. Appl. Phys. Exp. 2016, 9, 124101. [CrossRef]

21. Billah, M.M.; Hasan, M.M.; Jang, J. Effect of Tensile and Compressive Bending Stress on Electrical Performance of Flexible a-IGZO TFTs. IEEE Electron Device Lett. 2017, 38, 890-893. [CrossRef]

22. Jeong, H.J.; Kim, B.S.; Han, K.L.; Oh, S.; Park, J.S. Quantitative analysis of interface trap recovery caused by repetitive bending stress in flexible oxide thin-film transistors. Jpn. J. Appl. Phys. 2019, 58, 050906. [CrossRef]

23. Lee, W.-S.; Mativenga, M.; Kang, J.-S.; Tak, N.-K.; Choi, I.-C.; Kim, J.-Y.; Han, J.-U.; Choi, J.-H.; Hwang, M.-G. Spice model for detection of dynamic threshold voltage shift during failure analysis of oxide TFT-based AMD gate drivers. J. Soc. Inf. Display 2017, 25, 663-671. [CrossRef] 
24. Kim, W.-S.; Lee, Y.-H.; Cho, Y.-J.; Kim, B.-K.; Park, K.T.; Kim, O. Effect of Wavelength and Intensity of Light on a-InGaZnO TFTs under Negative Bias Illumination Stress. ECS J. Solid State Sci. Technol. 2017, 6, Q6-Q9. [CrossRef]

25. Jeong, J.K.; Yang, H.W.; Jeong, J.H.; Mo, Y.-G.; Kim, H.D. Origin of threshold voltage instability in indium-gallium-zinc oxide thin film transistors. Appl. Phys. Lett. 2008, 93, 123508. [CrossRef]

26. Jeong, H.-S.; Park, M.-J.; Kwon, S.-H.; Joo, H.-J.; Kwon, H.-I. Highly sensitive and selective room-temperature $\mathrm{NO}_{2}$ gas-sensing characteristics of $\mathrm{SnO}_{\mathrm{X}}$-based p-type thin-film transistor. Sens. Actuators B Chem. 2019, 288, 625-633. [CrossRef]

27. Jeong, H.J.; Han, K.L.; Ok, K.C.; Lee, H.M.; Oh, S.; Park, J.S. Effect of mechanical stress on the stability of flexible InGaZnO thin-film transistors. J. Inf. Disp. 2017, 18, 87-91. [CrossRef]

28. Chang, Y.H.; Yu, M.J.; Lin, R.P.; Hsu, C.P.; Hou, T.H. Abnormal positive bias stress instability of In-Ga-Zn-O thin-film transistors with low-temperature $\mathrm{Al}_{2} \mathrm{O}_{3}$ gate dielectric. Appl. Phys. Lett. 2016, 108, 033502. [CrossRef]

29. Dillon, A.C.; Ott, A.W.; Way, J.D.; George, S.M. Surface chemistry of $\mathrm{Al}_{2} \mathrm{O}_{3}$ deposition using $\mathrm{Al}\left(\mathrm{CH}_{3}\right)_{3}$ and $\mathrm{H}_{2} \mathrm{O}$ in a binary reaction sequence. Surf. Sci. 1995, 322, 230-242. [CrossRef]

30. Kamiya, T.; Nomura, K.; Hosono, H. Origins of High. Mobility and Low Operation Voltage of Amorphous Oxide TFTs: Electronic Structure, Electron. Transport Defects and Doping. J. Disp. Tech. J. Disp. Technol. 2009, 5, 468-483. [CrossRef]

31. Bae, H.; Choi, H.; Jun, S.; Jo, C.; Kim, Y.H.; Hwang, J.S.; Ahn, J.; Oh, S.; Bae, J.-U.; Choi, S.-J.; et al. Single-scan monochromatic photonic capacitance-voltage technique for extraction of subgap DOS over the bandgap in amorphous semiconductor TFTs. IEEE Electron Dev. Lett. 2013, 34, 1524-1526. [CrossRef]

32. Lee, J.M.; Cho, I.T.; Lee, J.H.; Kwon, H.I. Bias-stress-induced stretched-exponential time dependence of threshold voltage shift in InGaZnO thin film transistors. Appl. Phys. Lett. 2008, 93, 093504. [CrossRef]

33. Migliorato, P.; Chowdhury, M.D.H.; Um, J.G.; Seok, M.J.; Jang, J. Light/negative bias stress instabilities in indium gallium zinc oxide thin film transistors explained by creation of a double donor. Appl. Phys. Lett. 2012, 101, 123502. [CrossRef]

34. Revenant, C.; Benwadih, M.; Proux, O. Local structure around Zn and Ga in solution-processed In-Ga-Zn-O and implications for electronic properties. Phys. Status Solidi RRL 2015, 9, 652-655. [CrossRef] 